\title{
The Incentive Mechanism of Preferential Tax Policies to the Environmental Protection Industry
}

\author{
Shengting LI \\ International Business School \\ Shaanxi Normal University, SNNU \\ Xi'an, China
}

\author{
Xiaowei ZHOU \\ International Business School \\ Shaanxi Normal University, SNNU \\ Xi'an, China
}

\begin{abstract}
The environmental protection industry (EPI) has high policy sensitivity and is influenced by many factors, but the policies incentives to EPI have not attracted enough attention. This paper studies the incentive mechanism of preferential tax policies (PTP) to EPI by the method of system dynamics (SD). The supply and market concentration degree (MCD) of EPI is employed as the observation variable, and the level of PTP is set to $0 \%-80 \%$ (intervals of $20 \%$ ) to investigate the developmental trend of EPI. The results are as follows: PTP has a significant incentive effect to supply and MCD; the incentives of PTP to supply and MCD show decreasing and increasing scale effect respectively; Supply reaches the maximum on the level of $20 \%$ PTP.
\end{abstract}

Keywords-preferential tax policies (PTP); environmental protection industry (EPI); system dynamics (SD); market concentration degree (MCD)

\section{INTRODUCTION}

The total investment to environmental protection industry (EPI) from China's governance increased from 101.49 billion Yuan in 2000 to 921.98 billion Yuan in 2016, however, the output of China's EPI accounted for less than 3\% of GDP in 2016. In the meantime, the contribution rate of EPI reached more than $20 \%$ in the United States and other developed countries. It indicates that China's EPI still has considerable room for improvement. The structure of environment protection market (EPM) is not fully developed, small and micro enterprises account for more than $90 \%$, EPI has not yet formed significant scale effect and a reasonable degree of market concentration degree (MCD), the market mechanism has not yet taken effect completely. The EPI's overall R\&D capacity lags behind, and the market competition is not adequate. It can be understood that the growth effect of EPI is not obvious, although the investment and corresponding policy support keep growing. The EPI of China is still in the infancy period, no matter measured by the output or the market size of EPI. The preferential tax policies (PTP) can encourage enterprises to carry out technological innovation and thus promote the expansion of enterprise scale ${ }^{[1]}$. As EPI is typical

Shengting LI, Female, PhD candidate, Shaanxi Normal University, research direction: environmental economy, institutional economy; Xiaowe ZHOU, male, $\mathrm{PhD}$ supervisor, professor, Shaanxi Normal University, research direction: law and economics, institutional economy

Project fund: Research project on major theoretical and practical issues in social sciences of Shaanxi province "The ecological integration of industrial chain and the cultivation of the third party management market in the high-tech zone" (NO: 2019Z028); Shaanxi soft science research program "Mechanism and policy research on improving the quality of economic growth of Shaanxi government under the background of new normal" (NO. 2017KRM128) policy-sensitive, the influence of industrial policies is more significant for EPI than for other industries, but the mechanism of PTP incenting EPI is still unclear, resulting to the actual application effect of policy tools deviated from the expected. It is great significance to examine the dynamic mechanism of the influence of PTP on EPI from the perspective of system theory and to analyze the overall effect and trend of the development of EPI.

\section{REVIEW OF RELATED LITERATURE}

The influence of policy on industrial development has been a hot issue in economics. The research of Rodrik (2008) $)^{[1]}$ shows that the implementation effects of the same industrial incentive policies have not the same effect in different countries with a different history, culture, tradition, political and economic structure and other aspects. Nathan (2010) [2] further confirmed that the institution system factor has the obvious regulating function on long-term economic growth incentive by the function of reducing the possibility of rent-seeking. Furthermore, PTP has a significant positive effect on employment growth, enterprise development, infrastructure construction and economic growth (Freedman, 2013) [3] Warner (2011) ${ }^{[4]}$ proposed that lowering tax rate could promote production incentives and thus encourage enterprises to invest in innovative and R\&D activities. Riedel (2018) ${ }^{[5]}$ pointed out that the government should fund basic research that cannot be commercialized in time, so as to reduce the limitation of basic technology on practical technology improvement.

About China's industrial policies on EPI, Xiaoying HUANG (2017) ${ }^{[6]}$ analyzed the financial support efficiency of China's EPI and its influencing factors by DEA-Tobit method, founding that the pure technical efficiency of financial support to EPI was low; growth of EPI is highly dependent on national policies and has great regional heterogeneity. Ziwei LI (2018) [7] confirms that the tax support for strategic emerging industries is insufficient, and the tax incentives should be strengthened in various aspects to ensure the initial accumulation of emerging industries.

The above studies measured the impact of preferential tax policies on EPI from different aspects, but most of them chose the output or sales value of EPI as observation variables, and did not concern the variation of the market structure, whereas Industrial development is a process of pursuing multi-objective equilibrium, and the structural factors of market are also 
important indexes of industrial development, so there is still room for further research. This paper analyzed the modes and paths of tax incentives to EPI, and investigated the development of EPI from the perspective of industrial scale and market structure more comprehensively then described the mechanism and efficiency of PTP to promote EPI.

In this paper, EPI refers to the enterprises whose main business is providing technology, equipment, products and services related to environmental protection or pollution control. The tax incentives mainly include the reduction and refund of enterprise income tax and the tax preferential policies related to research and development investment.

\section{SYSTEM DYNAMICS MODEL OF EPI}

\section{A. SD Model Construction}

The development of EPI and the market are closely linked with each other. If only observing the output scale as a single indicator, it is impossible to examine the market in the structure and maturity of the variation trend, whereas the improvement and optimization of the market is the key variable of industrial upgrading and the core factor of ensuring the sustainable development of the industry. It is necessary to concern the market as a basic system, when examining the synergy between the factors based on the overall height, then it is possible to grasp the development path and evolution logic of EPI, to deep insight into the role of policy tool in path and extent, thus to optimize financial incentive and provide reliable theoretical support.

EPI is a relatively independent emerging policy-sensitive market with clear boundaries and has its own developmental regularity. From perspective of market equilibrium, this paper deconstructs EPM as follows: Market Demand subsystem and Market Supply subsystem. The demand subsystem includes enterprise procurement and government procurement. The output of the supply subsystem is affected by price, competition, demand and other factors, and maintains a dynamic balance with the demand subsystem.

System theory emphasizes integrity, complexity, nonlinearity, studies and speculates the internal relations and evolution of the system by abstracting and simulating. SD is a systematic research method combining path feedback, control simulation and quantitative analysis. In this paper, SD method was adopted to describe the development path and trend of EPI system under the influence of multiple external and internal factors, based on the relevant data of China's EPI from 2007 to 2016(data from the website of the national bureau of statistics, China environmental statistics yearbook and CSMAR database). The construction of this SD model is based on the following basic assumptions: (1)the basic model of EPM dynamic evolution system was constructed from the perspective of supply and demand balance, and assumed the initial state of supply and demand balance in 2007. (2)the two variables, Supply and MCD were employed as target variables to analyze the developmental trend of EPI. (3)PTP are described in the form of index.

\section{B. Parameter Setting}

Vensim PLE software is used to simulate the developmental trend of EPI, the simulation period is set to 10 years, and step length-DT is set to 1 year. The initial values of the horizontal variables (such as the QEPE, market Supply and Demand) were set to the statistical data in 2007, PTP are all expressed in index (without units), the units of other variables related to the revenue and expenditure are unified as 100 million Yuan. The simulation results are shown in Fig. 1 below.

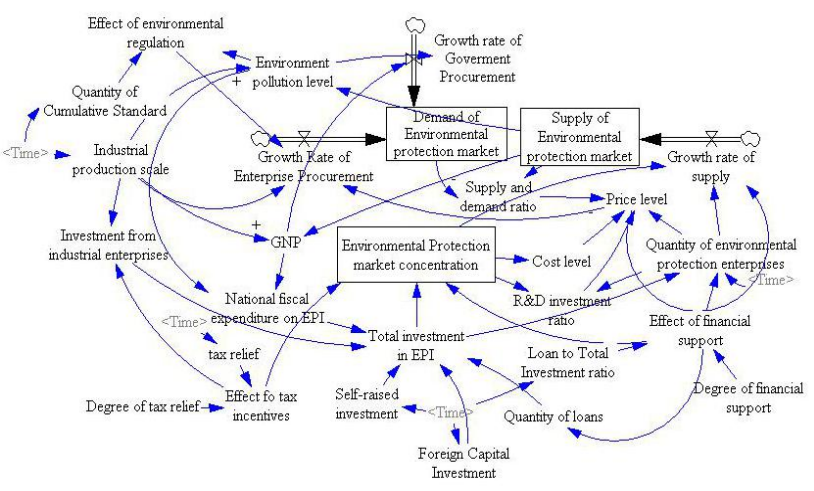

Fig. 1. The dynamic model of EPI invented by PTP

C. Description of Major Variables

TABLE I. SYSTEM MAIN VARIABLES DESCRIPTION

\begin{tabular}{l|l}
\hline \multicolumn{1}{c|}{ Relevant variable } & \multicolumn{1}{c}{ Variable declaration } \\
\hline Environment Pollution Level(EPL) & Referring to Shizhong TIAN (2017) [8], the statistical average of pollution index \\
\hline GNP & Gross National Product \\
\hline Industrial Production scale & Added value of the secondary industry \\
\hline Market Concentration degree(MCD) & The proportion of fixed assets(the three largest enterprises') in the whole EPI \\
\hline Quantity of Environmental Protection Enterprises(QEPE) & quantity of enterprises whose main business is environmental protection \\
\hline R\&D Investment ratio & R\&D investment/operating income of listed environmental protection enterprises \\
\hline Growth Rate of Enterprise Procurement & Growth rate of ratio of environmental protection expenditure of industrial enterprises listed \\
\hline Growth Rate of Government Procurement & Growth rate of total national fiscal expenditure on environmental protection \\
\hline Self-raised Investment & Self-raised funds for fixed asset investment in EPI \\
\hline Foreign Capital Investment & Foreign fixed assets investment to EPI \\
\hline Quantity of Cumulative Standard & Total of local environmental protection standards issued \\
\hline Tax Relief & Tax refund/payable tax of environmental protection enterprises listed \\
\hline Ratio of Loan to Total Investment & loan of fixed assets investment /total fixed assets investment of EPI \\
\hline
\end{tabular}




\section{Model Validation}

The model of SD is a simplified isomorphic one of real systems, whose purpose is to describe the operating characteristics of the system as a whole, in other word, the dynamic model cannot be duplicated exactly with the real system, therefore it is necessary to examine whether the model can accurately reflect the motion characteristics of the real system. The model structure suitability and model behavior suitability test can be employed to test. The dimensional conformance test in model structure suitability test is a built-in function of Vensim PLE software. Because automatic error and interruption, correction before running, the relevant error have been corrected. The method of parameter coincidence and trend coincidence was used to test the fit of model behavior. Some variables in Fig. 2 are filled with actual data, and others are obtained by fitting the actual data through system model simulation, as TABLE II was shown. Fit indicators of endogenous variables are acceptable mostly (above 75\%), which presents that the model can basically reflect the development reality of EPI.

TABLE II. FITTING TEST OF ENDOGENOUS VARIABLES

\begin{tabular}{c|c}
\hline relevant variable & $\mathbf{R}^{\mathbf{2}}$ \\
\hline GNP & 0.984 \\
\hline Total Investment in EPI & 0.913 \\
\hline National Fiscal Expenditure on EPI & 0.940 \\
\hline Investment from Industrial Enterprises & 0.781 \\
\hline Loan to Total Investment ratio & 0.812 \\
\hline Growth Rate of Government & 0.769 \\
\hline
\end{tabular}

The supply of EPI is adopted as the testing target for behavioral match test, according to the trend of the model fitting value and the actual value compared and analyzed. As can be seen from Fig. 2, the direction and situation of the simulation value are close to the actual value, it indicates that the model has a good behavior consistent with the real system and can reflect the characteristics of the real system.

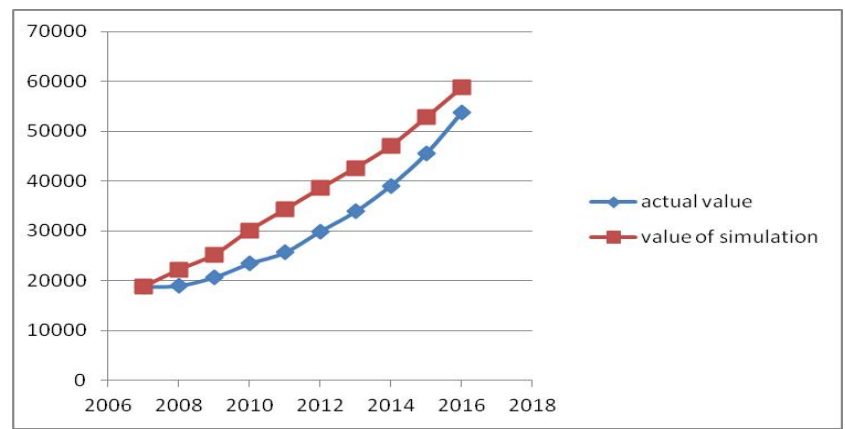

Fig. 2. Comparison of actual value and simulation value of supply trend of EPI

\section{E. Analysis of Simulation Result}

In this SD model, the base period is defined as the system state when tax incentives were preset to 0 . Tax incentives are embedded into the system by influencing the investment scale and MCD. When the random fluctuation function is used to adjust the tax incentives at the level of $0 \%$ to $20 \%$, the effect of tax incentives on Supply and on MCD are shown in Fig. 3 and Fig. 4 respectively.

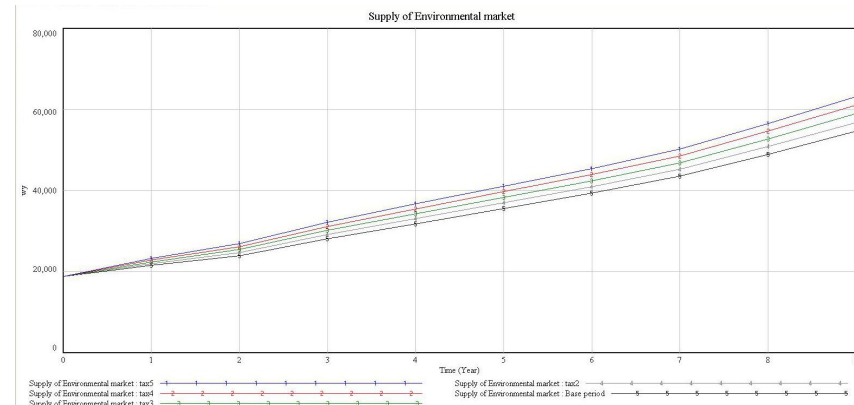

Fig. 3. Impact of PTP on Supply

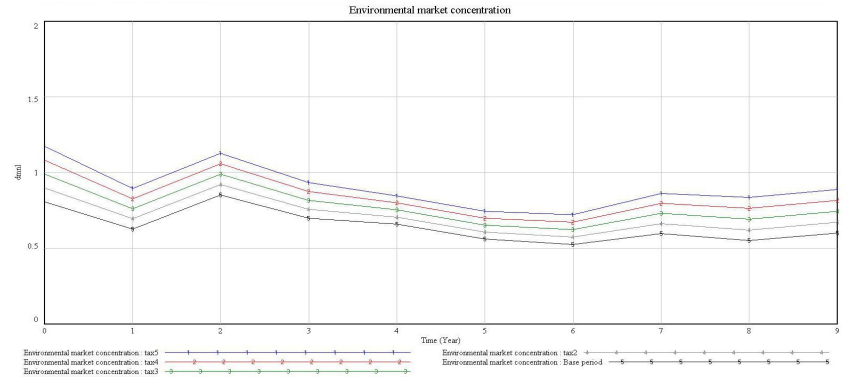

Fig. 4. Impact of PTP on MCD

As the figs showing above, the improvement effect on Supply gradually becomes significant after DT $=1 \sim 2$, under the incentive of PTP. On each incentive level, the average growth ratio of supply is between $7.58 \%$ and $9.80 \%$. When the tax incentive intensity $=20 \%$, the supply growth ratio reaches the maximum of $12.039 \%$ at the end of the simulation period, then gradually decreasing. But when the tax incentive intensity $=80 \%$, the supply growth rate drops to $8.85 \%$ at the end of the simulation period. It can be seen that the promotion of PTP on Supply shows a slow convergence trend. On the other hand, the level of MCD presents a unified fluctuation pattern in each simulation period. In the early stage of simulation, there is a big fluctuation, and then it gradually returns to a stable state. MCD shows an upward trend overall, and the promotion ratio is between $8.84 \%$ and $12.03 \%$, under the stimulus of tax incentives. The growth ratio of MCD shows obvious increasing scale effect characters with the continuous improvement of tax incentives. It can be concluded that the stimulus of PTP on EPI is obviously different in the two indexes of Supply and MCD. The promotion of PTP on the supply shows decreasing scale effect, and reaches the maximum when tax incentive is $20 \%$, whereas MCD incented by PTP keeps growing showing increasing scale effect.

\section{CONCLUSION ANALYSIS AND POLICY RECOMMENDATIONS ANALYSES}

PTP has a significant incentive effect on EPI. The growth ratio of Supply reaches the maximum when the tax incentive is $20 \%$, and then the scale effect decreases, whereas MCD incented by PTP is characterized by increasing scale effect. Therefore, excessive tax incentives have a limited promoting effect on Supply growth, which may lead to the drawback of too high MCD. 
For the above results, this paper believes the reasons following: From the perspective of the value chain, the action point of PTP is located at the end of the value chain, which can directly increase the final surplus of enterprises, thus enterprises can keep back more fund to carry out technological innovation and reproduction activities. The direct incentive of PTP on Supply is more significant than other means, this conclusion is consistent with the research of Shaoping LI (2017) [9]. On the other side, the major companies have a better absorptive capacity of financial resources and social influence factors, thus it is easier to obtain advantage support from the policy system, in the same time the policy support also has certain preference for major enterprises. Consequently, a positive feedback loop works, then the advantages of dominant enterprises are continuously amplified in the market, and the level of MCD is increased correspondingly.

The following proposal was put forward accordingly: First, pay attention to the function of PTP in promoting Supply of EPI. The government should sequentially to improve the tax incentives to the rational level about $20 \%$, especially for high-tech enterprises in EPI, in order to encourage capable enterprises to maintain more disposable funds to technological innovation and reproduction. Second, the government should simplify the forms and procedures of preferential policies application, enhance the transparency and operability of preferential policies, compile and publish the preferential policies for environmental protection enterprises formulated by different government departments in a column on the government website for the convenience of enterprises.

This paper investigated the unidirectional promotion of PTP to EPI, and it should be further studied that the interaction of various factors under different subdivision dimensions of policies.

\section{REFERENCES}

[1] D. Roderick. Same economics, different policy prescriptions [M] Beijing: Citic press, 2008: 97-142.

[2] N. Nathan. The Structure of Tariffs and Long- Term Growth [J]. Research of Environmental Science, 2010, 2 (4): 158 -194.

[3] M. Freedman. Targeted Business Incentives and Local Labor Markets [J]. Journal of Human Resources, 2013, (48): 311-344.

[4] J. M. Warner. Regional Development Discrepancies and Public Policy: Evaluating China's Western Development Strategy[R]. Working Paper, University of California, San Diego, 2011.

[5] N. Riedel. Quantifying International Tax Avoidance: A Review of the Academic Literature [J]. Review of Economics, 2018, 69(2): 169-181.

[6] Xiaoying Huang, Lirong Wen. Research on the Efficiency and Influencing Factors of Financial Support for the Enterprises in Energy-saving and Environmental Protection Industry [J]. Economy and Management, 2017, 31(1):45-50. (In Chinese)

[7] Ziwei LI. Incentive Mechanism of Independent Research and Development in Strategic Emerging Industries- a Case of Tax Policy of New Communication Network Industry [J]. Macroeconomics, 2018 (08):94-100. (In Chinese)

[8] Shizhong TIAN. The Comprehensive Evaluation of Environmental Pollution from the Perspective of Fiscal Decentralization in China: 1998-2015-An Empirical Study Based on the Panel Data of Provincial Industrial Pollution [J]. East China Economic Management, 2017, 31 (05):34-41. (In Chinese)

[9] Shaoping LI, Guangming LIU. Empirical Research on the Influence of Tax Preference on Energy Conservation and Environmental Protect Listed Companies' R\&D Investment [J]. Journal of Industrial Technological Economics, 2017, 36 (06):96-103. (In Chinese) 